\title{
A new culture medium based on genetic algorithms for Isochrysis galbana production relevant to hatcheries
}

\author{
J. Camacho-Rodríguez ${ }^{1}$ J. J. Gallardo-Rodríguez ${ }^{1}$ - M. C. Cerón-García ${ }^{1}$ F. García-Camacho ${ }^{1}$ - E. Molina-Grima ${ }^{1}$
}

Received: 30 April 2021 / Revised: 7 July 2021 / Accepted: 7 July 2021 / Published online: 4 September 2021

(c) The Author(s) 2021

\begin{abstract}
The nutrient content of a commercial seawater culture medium for growing the microalga Isochrysis galbana was optimized using a stochastic strategy based on genetic algorithms. For this, 210 experiments spread over seven generations were carried out. This strategy reduced the number of assays by more than $90 \%$ compared to a factorial design involving the optimization of twelve nutrients simultaneously. The optimized medium outperformed the reference medium in all aspects. The genetic algorithm strategy achieved a polyunsaturated fatty acids (PUFAs) productivity of $7.8 \mathrm{mg} \mathrm{L}^{-1}$ day $^{-1}$ in a continuous culture of I. galbana, corresponding to an increase of $15 \%$ compared to the commercial formulation. Carotenoids, on the other hand, increased by $50 \%$ d.w. In addition, PUFA yields were significantly improved, which allowed us to reduce the requirement of several nutrients, for instance, N (25\%), Mo (20\%), Mn (60\%), Co (60\%), and Cu (60\%).
\end{abstract}

Keywords Microalgae · Medium optimization · Genetic algorithm · Isochrysis galbana · Aquaculture · PUFAs · Fucoxanthin

\section{Introduction}

In recent decades the use of microalgae as a food supplement and as functional additives in marine aquaculture has grown rapidly. Species commonly used for animal feed in aquaculture include the genera Chlorella, Isochrysis, Phaeodactylum, Chaetoceros, Nannochloropsis, Tetraselmis, Dunaliella, Scenedesmus, Thalassiosira, and Skeletonema. The supply of microalgae is fundamental to certain aquaculture stages. Thus, microalgae are used to feed copepods, rotifers, and Artemia, which in turn are commonly used as the main live prey during the rearing of many larval marine species. Important progress has recently been made to allow for the direct use of microalgae as feed in all the mollusk life stages (Sirakov et al. 2015), as well as in the larval or juvenile stages of some fish (Vizcaíno et al. 2014). Raw microalgae biomass has been evaluated as feed for seabass (Dicentrarchus labrax), an alternative to oil and fishmeal, with substitution levels higher than $10 \%$ and $36 \%$, respectively (Cardinaletti et al. 2018), or even $50 \%$ in the case

M. C. Cerón-García

mcceron@ual.es

1 Department of Chemical Engineering and Research Centre CIAIMBITAL, University of Almería, 04120 Almería, Spain of red drum (Sciaenops ocellatus) (Perez-Velazquez et al. 2018). Accordingly, microalgae are generating great interest, not only because of their protein content, essential amino acids, and PUFAs, but also because of the presence of other compounds that give them an additional role as a functional ingredient for feed. In fact, numerous studies describe positive effects on muscle growth, coloration and oxidative state, intestinal ultrastructure and functionality, stress response, and disease resistance (Vizcaíno et al. 2014, 2016). From this perspective, using microalgae as a functional ingredient at a low inclusion level is seen as a promising strategy for improving the growth and general condition of the fish. Carotenoids are used in aquaculture as functional additives. Fish, like other animals, cannot synthesize carotenoids, so incorporating them to achieve natural pigmentation depends on their intake. Microalgal biomass has proven to be a valuable source of natural pigments (Camacho-Rodríguez et al. 2016; Sun et al. 2019). Microalgal carotenoids have been shown to carry out important biological functions in various fish species (Pereira da Costa and Campos Miranda-Filho 2020) due to their antioxidant properties (Pham et al. 2014; Vizcaíno et al. 2014), acting as an immune system modulator and influencing skin muscle pigmentation (Pham et al. 2014; Sales et al. 2020). 
Therefore, the main requirements that a microalga species must currently satisfy for use in aquaculture are a high total lipid content (13-33\%, dry weight), a considerable accumulation of polyunsaturated fatty acids (PUFAs) (Huerlimann et al. 2010; Camacho-Rodríguez et al. 2013; Vizcaíno et al. 2014), and a high pigment content. For this last requirement, chlorophylls, carotenoids, and phycobiliproteins are sought (Lubián et al. 2000). Isochrysis is well known as a source of different valuable pigments such as fucoxanthin, diadinoxanthin, and $\beta$-carotene (Borowitzka 2013; Ahmed et al. 2014) and a good potential source of docosahexaenoic acid (DHA) (Tzovenis et al. 1997). Consequently, for decades, Isochrysis galbana has been used worldwide in the aquaculture industry. For instance, Sukenik and Wahnon (1991) evaluated the biomass quality of this species three decades ago, with special attention to the lipid content, for its possible use in aquaculture.

To supply the microalgae, the aquaculture industry standard has been to use pond or bag systems, where the biomass is produced with no controlled conditions applied. Due to the low productivity and the high cost entailed in producing the necessary microalgae in situ, microalgae production is considered the main bottleneck to aquaculture industry development (Muller-Feuga 2000; Norsker et al. 2011; Acién et al. 2012). Given their critical role in aquaculture, more efficient microalgal biomass production systems using photobioreactors have been implemented in recent years (Naumann et al. 2013; Taelman et al. 2013).

Besides more efficient culture systems, the polyunsaturated fatty acid contents in microalgae can be enhanced by several strategies including the manipulation of the environmental parameters and using media formulations containing different extracts or growth stimulators (Hoffmann et al. 2010; Rohani-Ghadikolaei et al. 2012). However, nutrient availability and the medium formulation are the most important aspects to consider when the fatty acid and carotenoid contents are to be enhanced (Carvalho et al. 2006). The nutritional requirements vary depending on the species and its application. For example, in a culture destined for biofuel production, the objective is to accumulate fatty acids with the lowest possible level of unsaturation, establishing the maximum level of PUFAs at 1\% (Chisti 2007), while in aquaculture, a balance is sought between the PUFAs and protein. Therefore, for each application a tailored formulation must be obtained.

Media formulation optimization using genetic algorithms (GA) is an efficient search strategy that allows the culture medium to be improved in a faster way than using a factorial design. One cannot avoid the large number of experiments needed for a traditional strategy, even without considering the interaction between nutrients. In contrast, a GA methodology can be set to conduct a reasonable number of cultures at a time, and improvements are found within a few generations (Link and Weuster-Botz 2006; García-Camacho et al. 2011; Camacho-Rodríguez et al. 2015). This method has been used previously for the optimization of macroorganism growth (Marteijn et al. 2003) and also for microbial processes, with satisfactory results.

The aim of this paper was to determine the nutritional requirements for the growth of a previously selected marine microalgal strain using a stochastic search strategy through genetic algorithms. This strategy was based on optimizing the content of each nutrient in a previous culture medium (ALGAL; Aqualgae S.L., A Coruña, Spain), which is used to grow microalgae destined for aquaculture. PUFAs were selected as the objective function although carotenoids were also determined. Finally, the enhanced medium was validated in continuous culture to check the feasibility of using it for the large-scale culture of I. galbana.

\section{Materials and methods}

\section{Microorganism and culture maintenance}

The prymnesiophyte Isochrysis aff galbana (CCAP 927/1) was obtained from the Culture Centre for Algae and Protozoa (Cambridge, UK). Cultures (inocula) were aseptically maintained in photoautotrophic mode in 1-L Erlenmeyer flasks, with a liquid volume of $700 \mathrm{~mL}$ at $25 \pm 2{ }^{\circ} \mathrm{C}$. The flasks were continuously illuminated with an incident irradiance of $166 \mu \mathrm{mol}$ photons $\mathrm{m}^{-2} \mathrm{~s}^{-1}$, using white light lamps (Philips PL-32 W/840/4p). As the culture medium, the commercial marine formulation ALGAL was selected although the $\mathrm{KNO}_{3}$ was reduced to $0.4 \mathrm{~g} \mathrm{~L}^{-1}$. The original ALGAL medium formulation is $0.8 \mathrm{KNO}_{3} ; 0.027 \mathrm{NaH}_{2} \mathrm{PO}_{4} \cdot \mathrm{H}_{2} \mathrm{O}$; $0.0104 \mathrm{C}_{6} \mathrm{H}_{5} \mathrm{FeO}_{7} \cdot \mathrm{H}_{2} \mathrm{O} ; 0.00115 \mathrm{Na}_{2} \mathrm{MoO}_{4} \cdot 2 \mathrm{H}_{2} \mathrm{O} ; 0.00084$ $\mathrm{MnCl}_{2} \cdot 4 \mathrm{H}_{2} \mathrm{O} ; 0.0006 \mathrm{ZnCl}_{2} ; 0.0001 \mathrm{CoCl}_{2} \cdot 6 \mathrm{H}_{2} \mathrm{O} ; 0.00015$ $\mathrm{CuSO}_{4} \cdot 5 \mathrm{H}_{2} \mathrm{O} ; 0.011$ EDTA; 0.00208 Thiamine; 0.000027 Biotin; 0.000019 Cyanocobalamin (all quantities are in $\mathrm{g}$ $\mathrm{L}^{-1}$ ) (Aqualgae S.L., A Coruña, Spain). The macronutrient solution, previously sterilized in an autoclave at $126{ }^{\circ} \mathrm{C}$ for $20 \mathrm{~min}$, was added to natural seawater. The micronutrient solution was sterilized by filtering through a $0.22-\mu \mathrm{m}$ filter (Whatman GF/F, UK).

\section{Genetic algorithm: culture conditions and medium composition}

Assays were started using nutrient-depleted inoculum. The batch cultures were performed in this way for 14 days to assure that the macronutrients were consumed. One hundred-milliliter Erlenmeyer flasks with an effective volume of $60 \mathrm{~mL}$ were used. The flasks were agitated in an orbital shaker at $100 \mathrm{rpm}$ without bubbling, under continuous illumination $\left(166 \mu \mathrm{mol}\right.$ photons $\left.\mathrm{m}^{-2} \mathrm{~s}^{-1}\right)$ and at a temperature 
of $25 \pm 2^{\circ} \mathrm{C}$. Culture growth was evaluated after seven days. In a previous work (Camacho-Rodríguez et al. 2020), several assays were carried out to find the inhibiting concentration (upper limit) for each individual component included in the commercial ALGAL medium. The range of concentrations tested for each nutrient is shown in Table $1 . \mathrm{CO}_{2}$ mass transfer was calculated using an empirical equation for $\mathrm{k}_{\mathrm{L}} \mathrm{a}$ in shaken flasks (Veljkovic et al. 1995). Values of $154 \mathrm{~h}^{-1}$ implied $\mathrm{CO}_{2}$ supply of $1.6 \mathrm{mmol} \mathrm{CO}_{2} \mathrm{~h}^{-1} \mathrm{~L}^{-1}$. Thus, $\mathrm{CO}_{2}$ mass transfer was similar to the one obtained in typical PBRs (Rubio et al. 1999).

The optimization of the culture medium composition was carried out through a four-stage cyclic genetic algorithm based on the creation of new populations through "genetic manipulation" (García-Camacho et al. 2011). For this, GALOP software (Institute of Biotechnology, Jülich, Germany) was used (Beste et al. 1997). The first stage of this process consisted of randomly choosing a first generation (randomization) within the limits established in the nutrient concentration range (Table 1). The twelve components of the culture medium were the variables encoded in binary character strings. The media formulation is known as the "chromosome" for each experiment. For the subsequent generation, crosses were made based on the best chromosome obtained from the previous generation. The productivity of the PUFAs (PPUFAs) was selected as the selection criterion. The "Roulette" selection method (Muffler et al. 2007), with an exchange rate or genetic crossing of 0.95 and a mutation probability of 0.01 , was selected. In each generation, fifteen duplicate individuals were evaluated in parallel (a total of 30 cultures).

\section{Comparison of the best media for continuous culture in PBRs}

Once the culture medium formulation was optimized by means of the genetic algorithm, I. galbana was continuously cultivated to compare the best medium obtained from the original ALGAL medium using this strategy; the nitrate level was set to an initial concentration of $4 \mathrm{mM}$ (Camacho-Rodríguez et al. 2020). These experiments were carried out in indoor bubble columns with a $1.8 \mathrm{~L}$ capacity, an inner diameter of $0.07 \mathrm{~m}$, and a height of $0.5 \mathrm{~m}$. The PBRs were illuminated simulating a circadian cycle with a maximum incident irradiance of $1000 \mu \mathrm{mol}$ photons $\mathrm{m}^{-2} \mathrm{~s}^{-1}(12: 12 \mathrm{~h}$; light:dark) using white light lamps (Philips PL-32 W/840/4p). Six lamps were placed vertically aligned around the outside surface of the cylindrical vessel. Aeration was supplied to the base of the column at $0.5 \mathrm{vvm}$. The temperature was maintained at $25.0 \pm 0.5^{\circ} \mathrm{C}$ using refrigerated water as the cooling agent. The $\mathrm{pH}$ was maintained in the 7.8 to 8.0 range by injecting carbon dioxide on demand. The experiments started with

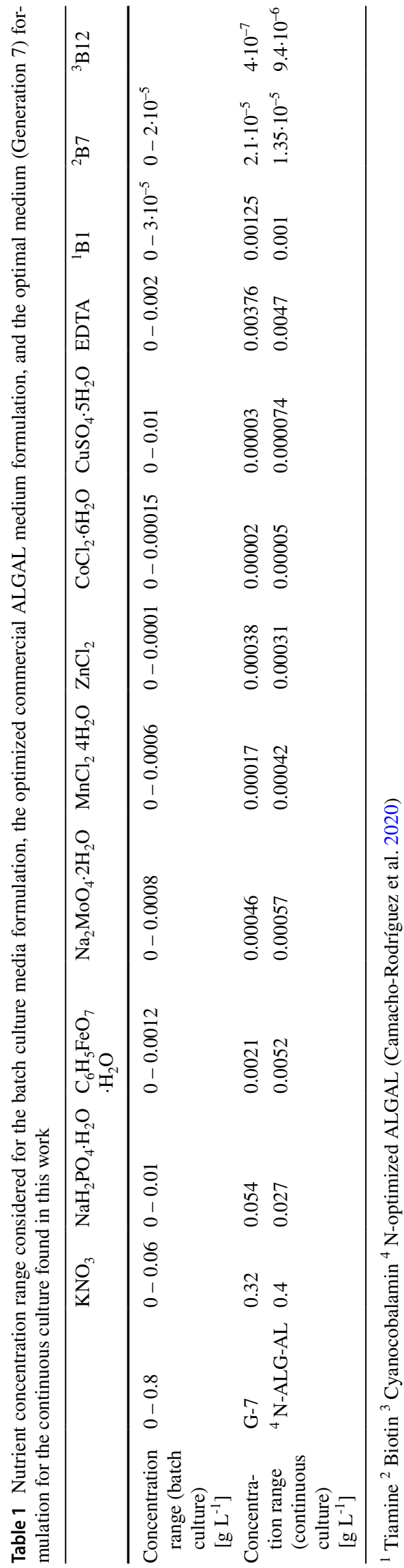


a biomass concentration of $0.17 \mathrm{~g} \mathrm{~L}^{-1}$ in discontinuous mode. When the biomass reached a concentration of $1 \mathrm{~g}$ $\mathrm{L}^{-1}$, the continuous mode started. The dilution rate was fixed at $0.3 \mathrm{day}^{-1}$ since this value was previously determined to be optimum for the N-ALGAL medium under these conditions (Camacho-Rodríguez et al. 2020).

\section{Analytical procedures}

The monitoring of growth was carried out measuring optical density $(750 \mathrm{~nm})$. In the continuous cultures, the biomass concentration was determined daily. Samples were periodically taken for biomass dry weight determination. The culture samples were centrifuged at $6640 \mathrm{rcf}$ for $5 \mathrm{~min}$. Then they were washed with $0.5 \mathrm{M}$ ammonium bicarbonate (Zhu and Lee 1997) with $5 \mathrm{~mL}$ of this solution was used per $g$ of wet biomass. Two washes were performed to remove the salts. The biomass samples were freeze-dried and stored at $-20^{\circ} \mathrm{C}$. The fatty acid content was determined by gas chromatography using an adaptation of the method of Rodríguez-Ruiz et al. (1998). In brief, $8 \mathrm{mg}$ of biomass was ground up with an equivalent mass of alumina. It was then methylated by adding $1 \mathrm{~mL}$ of hexane, $50 \mu \mathrm{L}$ of a standard grade acid solution (C19:0 nonadecanoic acid), and $1 \mathrm{~mL}$ of the methylating mixture (acetyl chloride-methanol 5:100 v:v). To carry out the methylation, the solution was heated in a thermoblock at $105^{\circ} \mathrm{C}$ for $20 \mathrm{~min}$ and stirred once with a vortex shaker after $10 \mathrm{~min}$. The sample was allowed to cool to room temperature before adding $1 \mathrm{~mL}$ of distilled water. Then, it was centrifuged at $3500 \mathrm{rpm}$ for $5 \mathrm{~min}$. The hexane phase was analyzed by gas chromatography. Similarly, the carotenoid content was determined by HPLC using the saponification-extraction method described by Cerón-García et al. (2018). To do this $5 \mathrm{mg}$ of biomass was mixed with $5 \mathrm{mg}$ of alumina and an equal volume of glass beads $(0.5 \mathrm{~mm}$ glass beads, BioSpec Products Inc., USA) in $1 \mathrm{~mL}$ of a three-component solution containing hexane (18\%), ethanol $(76 \%)$, and $\mathrm{KOH}$ (10\% mass fraction) in water $(6 \%)$. Once the three-component mixture had been added, the saponification was performed for $2 \mathrm{~min}$ in a mini-beadbeater (MiniBeadBeater-16, Model 607EUR, BioSpec Products Inc., USA). It was then centrifuged for $2 \mathrm{~min}$ at $12,000 \mathrm{rpm}$ in an Eppendorf centrifuge (Eppendorf AG 22,331, Germany) and $800 \mu \mathrm{L}$ (approx.) of the supernatant was transferred to the chromatography vials. The pigment content was measured directly in an HPLC-fluorescence detector (RF-10A XL, Shimadzu, Japan) using the method described by Cerón et al. (2007). Analytical standards of fucoxanthin and diadinoxanthin were acquired from DHI (Denmark), while $\beta$-carotene was obtained from Sigma Chemical Co. (USA).

\section{Kinetic parameters}

The biomass productivity $\left(P_{\mathrm{b}}, \mathrm{g} \mathrm{L}^{-1}\right.$ day $\left.^{-1}\right)$ was calculated by Eq. 1 as the difference between the initial and final biomass concentration $\left(C_{\mathrm{X}}, \mathrm{g} \mathrm{L}^{-1}\right)$, divided by the cultivation time ( $t$, days):

$P_{\mathrm{b}}=\frac{C_{\mathrm{Xfinal}}-C_{\text {Xinitial }}}{t}$

The productivity of the PUFAs $\left(P_{\text {PUFAs }}\left(\mathrm{mg} \mathrm{L}^{-1}\right.\right.$ day $\left.\left.^{-1}\right)\right)$ was calculated as:

$P_{\text {PUFAs }}=P_{\mathrm{b}} \cdot Y_{\mathrm{PUFAs} / \mathrm{X}}$

where $Y_{\mathrm{PUFAs} / \mathrm{X}}$ is the PUFA yield of the biomass (g PUFAs $\mathrm{g}^{-1}$ biomass).

The productivity of carotenoids $\left(P_{\text {carot }}\left(\mathrm{mg} \mathrm{L}^{-1} \mathrm{day}^{-1}\right)\right)$ was calculated according to Eq. 3:

$P_{\text {carot }}=P_{\mathrm{b}} \cdot Y_{\text {carot } / \mathrm{X}}$

where $Y_{\text {carot/ } \mathrm{X}}$ is the carotenoid yield of the biomass (g carot $\mathrm{g}^{-1}$ biomass).

The yields for the PUFAs and the carotenoids with respect to the main substrates (nitrogen and phosphorus) achieved in the continuous cultures were calculated according to Eqs. 4 and 5, as the product of $Y_{\text {PUFAs/X }}$ and $Y_{\text {carot } / \mathrm{X}}$, respectively, and the concentration of biomass in the culture $\left(C_{\mathrm{X}}, \mathrm{g} \mathrm{L}^{-1}\right)$ divided by the concentration of the nutrient in the medium $\left(C_{S}, \mathrm{~g} \mathrm{~L}^{-1}\right)$ :

$Y_{\mathrm{PUFAs} / \mathrm{S}}=Y_{\mathrm{PUFAs} / \mathrm{X}} \cdot \frac{C_{\mathrm{X}}}{C_{\mathrm{S}}}$

$Y_{\mathrm{carot} / \mathrm{S}}=Y_{\mathrm{carot} / \mathrm{X}} \cdot \frac{C_{\mathrm{X}}}{C_{\mathrm{S}}}$

\section{Economic evaluation}

An economic balance was made based on the optimum formulation in which the cost of each nutrient, as well as the requirements of each, has been calculated. The cost of each component is based on the technical grade product at laboratory size (100-1000 g). The reference value was that of the ALGAL medium, which was around $1 €$ per L. The aim was to determine if the productivity improvements due to the new formulation could imply higher or lower cost. As components have very different market prices, the medium cost is more sensitive to changes of some components. A detailed description of the procedure can be found elsewhere (Camacho-Rodríguez et al. 2020). 


\section{Statistical analysis}

All experiments were carried out in triplicate. The experimental results were given as the average values of the three independent experiments and their standard deviation. Statistical data analyses were performed using the Statgraphics Centurion XVI software package. The normality and homogeneity analyses were performed using the Kolmogorov-Smirnov and Levene tests, respectively. The average values of $P_{\mathrm{b}}$ and $P_{\text {PUFAs }}$ have been determined with their corresponding standard deviations. For this, a one-way ANOVA was conducted on the average values of $P_{\mathrm{b}}$ and $P_{\text {PUFAs }}$ in each experiment. A confidence level of $95 \%$ and $p$ values $<0.05$ were considered statistically significant.

\section{Results}

\section{Culture optimization process}

In Fig. 1A, a significant increase in the average biomass productivity value for each successive generation $(p=0.00001)$ can be seen. The software determined the medium formulations for each generation based on the best result from the previous generation.

From the average of all the mediums within a generation, the maximum biomass productivity value $\left(56 \mathrm{mg} \mathrm{L}^{-1}\right.$ day $\left.^{-1}\right)$ was reached in generation 5, and it was almost three times higher than the best value achieved in the initial generation. Similarly, in Fig. 1B, we can see the average PUFA productivity values for all the experiments, as well as the maximum value in each generation. Each generation (up to the sixth) produced an enhancement compared to the previous generation (significant differences with a 95\% confidence level, $p<0.05$ ). The maximum intergenerational PUFA productivity average was reached in generation 6 , an average value of $1.65 \mathrm{mg} \mathrm{L}^{-1} \mathrm{day}^{-1}$. The maximum individual value was also achieved in a culture medium from this generation, with a value of $1.96 \mathrm{mg} \mathrm{L}^{-1} \mathrm{day}^{-1}$. The improvement obtained in the PUFA productivity in this generation was twice that of the initial value (Fig. 1B).

Figure 2 shows the values obtained for the productivity of the PUFAs in all the experiments carried out over the 7 generations. The values achieved in generations 6 and 7 have been highlighted to show that no improvement was observed compared to the values obtained in the previous three generations. That is why a decision was made to terminate the genetic algorithm optimization at this point.

As can be seen in Fig. 3, the values of the main $I$. galbana carotenoids (fucoxanthin, diadinoxanthin, and $\beta$-carotene) have been represented; these correspond to the experiments with the best culture media for each generation (according to the selection criteria).
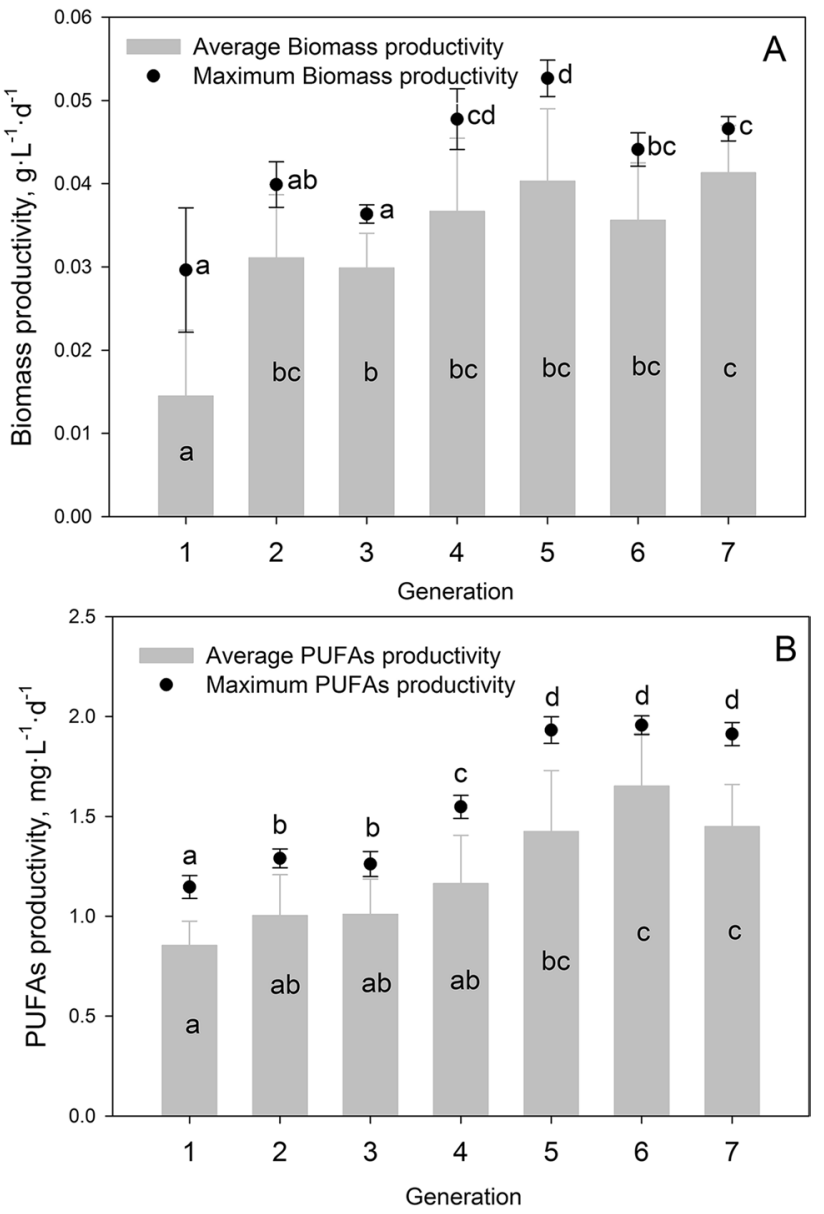

Fig. 1 Average and best productivity in each generation of the optimization process. (A) Biomass productivity; (B) PUFA productivity. Different letters indicate significant differences $(p$-value $<0.05)$ within each treatment

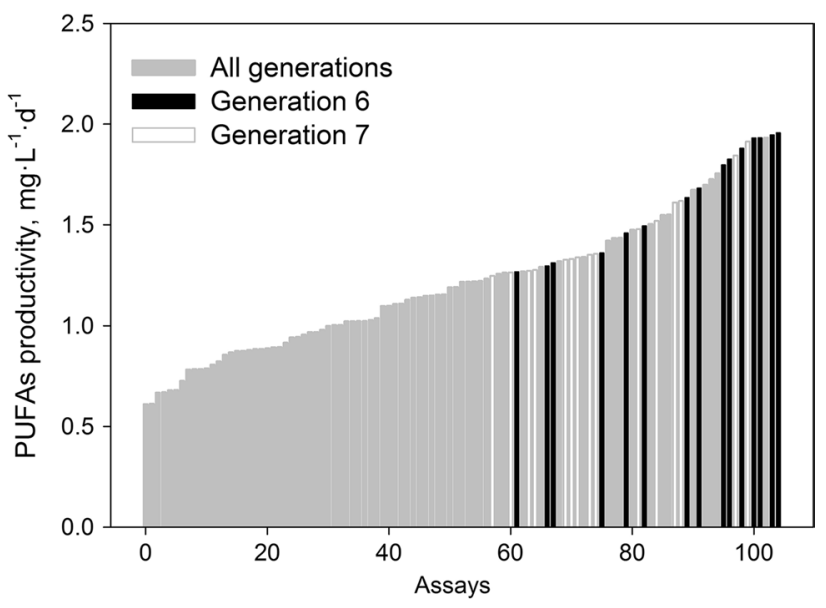

Fig. 2 PUFA productivity in all the experiments carried out during the optimization process 


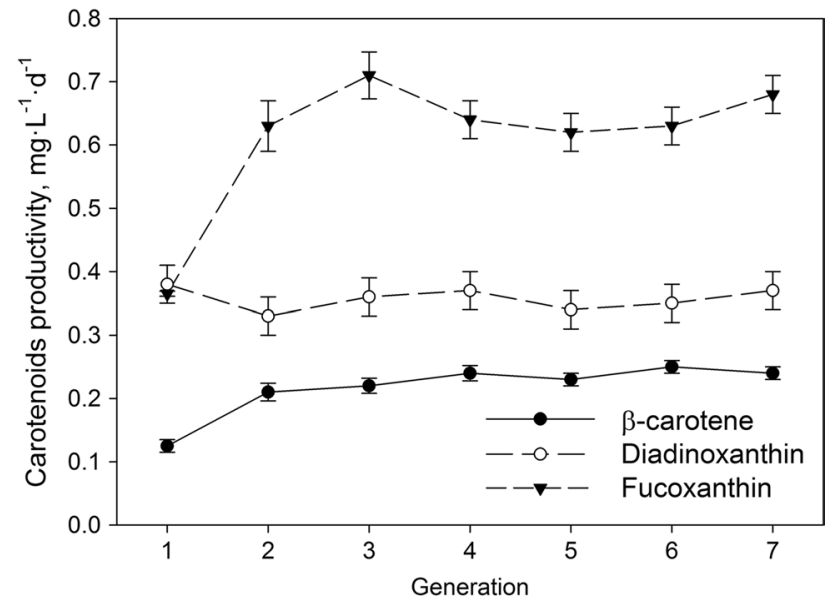

Fig. 3 Productivity of carotenoids (fucoxanthin, diadinoxanthin, and $\beta$-carotene) for the best culture media in each generation

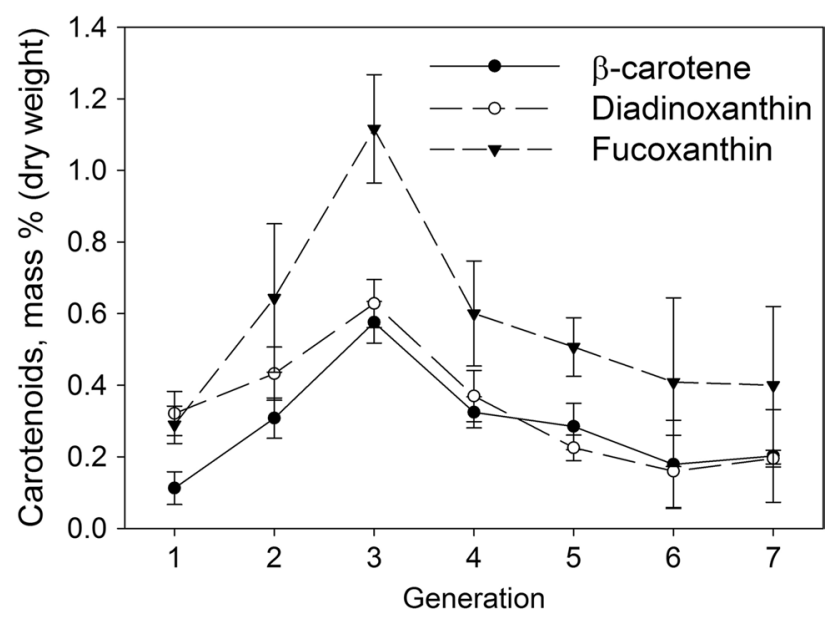

Fig. 4 Content of carotenoids (fucoxanthin, diadinoxanthin, and $\beta$-carotene) expressed in mass \% (dry weight) for the best culture media in each generation

Diadinoxanthin productivity did not suffer significant differences for the different media tested, obtaining an average value of $0.37 \mathrm{mg} \mathrm{L}^{-1} \mathrm{day}^{-1}$. However, with respect to the $\beta$-carotene and fucoxanthin contents, a significant increase in productivity was observed after the first generation, although after the second and third generation, no significant variation could be appreciated between generations.

In Fig. 4, the percentage in mass has been plotted for the best culture media in each generation. As one can see, the biomass containing the highest carotenoid content was found in the third generation. From G-4, steady composition was observed for all the main I. galbana carotenoids.

\section{Continuous culture with the best culture media}

The best culture medium proposed by the genetic algorithm obtained in generation 7 was further evaluated under continuous culture conditions. It was compared with the nitrogen-optimized ( $4 \mathrm{mM}$ of $\mathrm{N}$ ) ALGAL medium. The biomass productivity values were almost identical $(0.212$ and $0.211 \mathrm{~g}$ $\mathrm{L}^{-1} \mathrm{day}^{-1}$ ) for the best G-7 and N-optimized ALGAL media (Table 2). There was no significant difference in the biomass productivity improvement between the two media since the ALGAL medium was previously improved (with nitrogen) and our objective function here was the PUFA content. Under continuous mode, the biomass cultivated using the best G-7 medium achieved an accumulation of $3.69 \%$ (dry weight), $15 \%$ higher than that achieved with the N-optimized ALGAL medium, which was $3.22 \%$ (Table 2). Therefore, the productivity of the PUFAs obtained with the best G-7 medium was also 15\% higher than that achieved with the N-optimized ALGAL medium, with values of 7.8 and $6.8 \mathrm{mg} \mathrm{L}^{-1} \mathrm{day}^{-1}$, respectively (Table 2 ). This value of 7.8 implies a PUFA content of $42 \%$, based on the total fatty acids. With respect to carotenoids, the accumulation of fucoxanthin when using the best G-7 medium increased from 0.54 to $0.81 \%$ (dry weight) compared to using the $\mathrm{N}$-optimized ALGAL medium (Table 2). In the case of diadinoxanthin, the increase achieved was similar, from 0.05 to $0.08 \%$ (dry weight) with the best G-7 medium (Table 2). The $\beta$-carotene content was not affected by varying the culture medium composition. As a result of the higher fucoxanthin and diadinoxanthin contents, the total carotenoid content was 50\% higher in the best G-7 medium compared to the $\mathrm{N}$-optimized ALGAL medium (Table 2). If we compare the results of the different culture modes, we find that the continuous mode favored the accumulation of carotenoids. With the best G-7 medium, the biomass produced in continuous
Table 2 Biomass and PUFA productivities (in $\mathrm{mg} \cdot \mathrm{L}^{-1} \cdot \mathrm{d}^{-1}$ ), accumulation of PUFAs and carotenoids in the biomass (\%, dry mass), and the total carotenoids (\%, dry mass) for I. galbana grown in con- tinuous mode, comparing the best medium proposed by the genetic algorithm (best of G-7) and the N-optimized ALGAL commercial medium (Camacho-Rodríguez et al. 2015)

\begin{tabular}{lllllll}
\hline Medium & \% PUFAs & $\mathrm{P}_{\mathrm{B}}$ & $\mathrm{P}_{\text {PUFAs }}$ & $\%$ fucoxanthin & $\begin{array}{c}\% \text { diadinoxan- } \\
\text { thin } \beta \text {-carotene }\end{array}$ & $\begin{array}{c}\% \text { total } \\
\text { carot- } \\
\text { enoids }\end{array}$ \\
\hline Best G-7 & 3.69 & 0.212 & 7.8 & 0.81 & 0.08 & 0.04 \\
N-ALGAL & 3.22 & 0.211 & 6.8 & 0.54 & 0.05 & 0.04 \\
\hline
\end{tabular}


mode contained $1.04 \%$ carotenoids; this is a $20 \%$ improvement compared to batch mode.

\section{Economic balance: culture media composition}

The concentration of each nutrient in the best G-7 and $\mathrm{N}$-optimized ALGAL media tested under continuous culture mode is shown in Table 1. Important differences can be observed between them. Based on this, the cost of each ingredient has been calculated. The market price and the requirement of each ingredient were used to estimate a medium cost (see the "Materials and methods" section). Thus, a cost saving of around $25 \%$ was obtained for the algorithm-optimized medium compared to the $\mathrm{N}$-optimized ALGAL medium (see Fig. 5). Figure 5 shows the PUFA yield ( $\mathrm{Y}_{\text {PUFAS/X }}$, gPUFAs/gX) with respect to several nutrients, including nitrogen (as the main macronutrient) and micronutrients such as iron, manganese, and cyanocobalamin (vitamin B12). The maximum PUFA yield for the best G-7 medium has been relativized in relation to the N-optimized ALGAL medium. The improvement in the PUFAs/N yield was $42 \%$; in the cases of $\mathrm{Fe}$ and $\mathrm{Mn}$, the yield improved by around 3 times, whereas for B12, it improved by almost 27 times.

\section{Discussion}

Culture medium formulation is a critical factor in bioprocesses since it affects both microalgal growth and composition. Culture optimization using genetic algorithms is

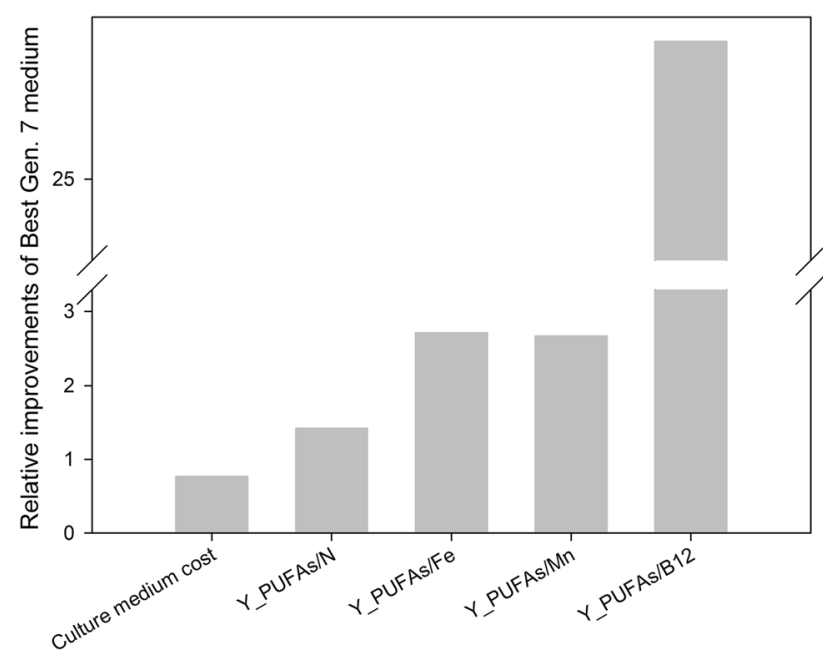

Fig. 5 Relative improvement in medium cost and PUFA yield with respect to the nutrients $\left(\mathrm{Y}_{\mathrm{PUFAs} / \mathrm{X}}\right)$ obtained in a continuous culture of I. galbana comparing the best G-7medium (genetic algorithm) with the N-optimized ALGAL. Medium costs were calculated based on technical grade nutrients $(100-1000 \mathrm{~g})$ usually conducted for the sole purpose of optimizing cell growth (e.g., Marteijn et al., 2003; García-Camacho et al., 2011; Camacho-Rodríguez et al., 2015;). The product in our study is not directly linked to growth; instead, the objective function we aimed to maximize was the productivity of the PUFAs, although we also monitored the accumulation of carotenoids. The maximum attained biomass productivity (56 $\mathrm{mg} \mathrm{L}^{-1}$ day $^{-1}$ ) improved importantly the result of our internal reference. Lin et al. (2007) achieved similar biomass productivity values, $57.4 \mathrm{mg} \mathrm{L}^{-1}$ day $^{-1}$, but a lower PUFA content, with I. galbana grown in Walne's medium. The conditions that favor the accumulation of PUFAs (primary metabolites) are not necessarily the same conditions that induce the accumulation of carotenoids. However, one can observe that in each successive generation, culture growth was favored at the same pace as the primary metabolite (PUFAs) accumulation (Fig. 1A and B). Carotenoids are secondary metabolites, so stress conditions in the culture are required for their accumulation to increase. Within the first 3 generations, an important increase in total carotenoids productivity was also observed in our study. However, there were no further improvements from this G3. Fucoxanthin contributed almost exclusively to this increase. Conversely, carotenoids mass fraction decrease from G3 (where a maximum was observed). Nevertheless, the carotenoid results of final generations are in the range of the referenced values for this species and were higher than our control culture. For instance, Ahmed et al. found around $0.5 \%$ of carotenoids for I. galbana (Ahmed et al. 2014), whereas Sun et al. (2019), in their comparative analysis of 16 different I. galbana strains, reported higher values $(0.9-1.6 \%)$. In our case, the formulations assayed showed a highly variable total carotenoid content, ranging between 0.4 and $2.3 \%$.

The positive results obtained in batch cultures carried out in shaken flasks maintained in the continuous assay since more PUFAs (15\%) and carotenoids (50\%) were produced if we compared the proposed medium to the N-ALGAL. As expected, for the proposed medium the scaled-up continuous culture improved the productivity of the batch culture ( 0.212 vs $\left.0.056 \mathrm{~g} \mathrm{~L}^{-1} \mathrm{day}^{-1}\right)$. This is a considerable biomass productivity. For instance, Patil et al. (2007), evaluating $I$. galbana grown in the "Z8" medium, achieved significantly lower biomass productivity values $\left(0.16 \mathrm{~g} \mathrm{~L}^{-1} \mathrm{day}^{-1}\right)$ and a PUFA content of $39.9 \%$ (of the total fatty acid content).

Nutrient efficiency in synthesizing the PUFAs, expressed as the yield of PUFAs with respect to the different nutrients ( $\left.\mathrm{Y}_{\mathrm{PUFAS} / \mathrm{X}}, \mathrm{gPUFAs} / \mathrm{gX}\right)$, is an important economic parameter that can be used to select the most appropriate sources of a certain nutrient (Acién et al. 2012). Besides, it can be used to compare different formulations on the basis of a certain objective function. If we consider the composition of the media evaluated under continuous culture mode (Table 2), we can see that the nitrogen concentration in both media 
increased significantly with respect to the reference medium. However, for the best G-7 medium, a similar biomass was obtained with $25 \%$ less nitrogen. This might be related to the fact that a PUFA productivity of $7.8 \mathrm{mg} \mathrm{L}^{-1}$ day $^{-1}$ was obtained for the best G-7 medium, which was $15 \%$ higher than that for the N-optimized ALGAL medium. Regarding the phosphorus concentration in the culture medium, the optimal value at which the genetic algorithm converged was $0.054 \mathrm{~g} \mathrm{~L}^{-1}$; this is twice the concentration used by the N-optimized ALGAL medium $\left(0.027 \mathrm{~g} \mathrm{~L}^{-1}\right)$. In similar studies where microalgal medium were optimized, the phosphorus concentration also increased significantly (Gallardo Rodríguez et al. 2009; García-Camacho et al. 2011; LópezRosales et al. 2015).

Micronutrients were also significantly changed during the optimization process. Micronutrients are essential for growth although their influence is not always easy to establish. Their requirements are influenced by interactions with other nutrients and culture conditions such as the sources or availability of nutrients, the light intensity, and the competition between different nutrients within the same metabolic pathway. All of these factors regulate cellular metabolism, which can lead to the accumulation of certain metabolites that can be further used (Procházková et al. 2014). Chen et al. (2011) carried out a daily determination of the micronutrient concentrations in a Dunaliella tertiolecta culture medium, finding measurable consumption in a few of them (i.e., Mo and Co). However, much of the initial content remained after 7 days of cultivation. This gives us an idea of the importance of these micronutrients for microalgal growth, but it also shows that they are formulated to excess on many occasions. Although micronutrients are formulated at low concentrations, their cost can be quite important. For instance, iron requirements, which are relatively high, were shown to influence the final medium cost (Stefels and van Leewe 1998). The optimized G-7 medium allowed us to reduce the iron requirement 2.5 times without reducing the biomass or PUFA productivity. Similarly, the genetic algorithm significantly reduced the concentration of other micronutrients (see Table 2). In the present study, the Mo content in the optimized G-7 medium was $20 \%$ lower than in the N-optimized ALGAL medium. This reduction was even greater in the cases of $\mathrm{Mn}, \mathrm{Co}$, and $\mathrm{Cu}$, all of which had a $60 \%$ lower content than in the ALGAL medium. Nevertheless, not all the micronutrient concentrations were reduced; for instance, the Zinc content was slightly increased.

The effect of group B vitamins on microalgal growth has been extensively studied although their mechanisms of action are not totally clear. Fábregas et al. (1998) found that Haematococcus lacustris needs thiamine, biotin, and cyanocobalamin (although requirements are low), while Gong and Chen (1997) found that these vitamins had no effect on growth in the same species. Based on the results obtained in the present study, we can conclude that vitamin B12 is necessary for the growth and accumulation of PUFAs in I. galbana, since the media formulation that lacked it showed poor performance. The thiamine and biotin content increased slightly in the best G-7 medium with respect to the commercial medium, although the cyanocobalamin content could be reduced 20 times without affecting biomass or PUFA productivity.

\section{Conclusions}

The use of a stochastic search strategy, in this case a genetic algorithm, has allowed us to formulate a new culture medium for Isochrysis galbana that improves the PUFA content both in batch and continuous mode. The biomass and carotenoid productivity were also improved for this species with respect to the reference medium (nitrogen-optimized ALGAL). During the genetic algorithm optimization, 210 individual cultures were carried out. This strategy reduced the number of assays by more than $90 \%$ compared to a factorial design with twelve nutrients and twelve levels. The new medium proposed by the genetic algorithm increased the productivity of the PUFAs in continuous culture by $15 \%$, reducing the cost of biomass production by $24 \%$ compared to the N-optimized ALGAL medium. Carotenoids increased by $50 \%$ (d.w.) in the proposed medium, although other formulations assayed increased by only $2.3 \%$ (d.w). We showed that a reduction in several nutrient concentrations, such as nitrogen (by 25\%), molybdenum (by 20\%), and manganese, cobalt, and copper (by $60 \%$ each), did not reduce PUFA and carotenoid productivity, but actually increased it. Consequently, a richer I. galbana biomass destined for aquaculture can be produced at lower cost.

Funding Open Access funding provided thanks to the CRUE-CSIC agreement with Springer Nature. This research was financially supported by the General Secretariat of Universities, Research and Technology of the Andalusian Regional Government, AGR-5334 and P18-RT-2477 (Biopromar) and was co-financed with FEDER funds.

Data availability All data generated or analyzed during this study are included in this published article.

\section{Declarations}

Conflict of interest The authors declare no competing interests.

Open Access This article is licensed under a Creative Commons Attribution 4.0 International License, which permits use, sharing, adaptation, distribution and reproduction in any medium or format, as long as you give appropriate credit to the original author(s) and the source, provide a link to the Creative Commons licence, and indicate if changes were made. The images or other third party material in this article are 
included in the article's Creative Commons licence, unless indicated otherwise in a credit line to the material. If material is not included in the article's Creative Commons licence and your intended use is not permitted by statutory regulation or exceeds the permitted use, you will need to obtain permission directly from the copyright holder. To view a copy of this licence, visit http://creativecommons.org/licenses/by/4.0/.

\section{References}

Acién FG, Fernández JM, Magán JJ, Molina E (2012) Production cost of a real microalgae production plant and strategies to reduce it. Biotechnol Adv 30:1344-1353

Ahmed F, Fanning K, Netzel M, Turner W, Li Y, Schenk PM (2014) Profiling of carotenoids and antioxidant capacity of microalgae from subtropical coastal and brackish waters. Food Chem 165:300-306

Beste H, Fackeldey M, Willems M, Stockman L, Weuster-Botz D (1997) Optimization of fermentation medium composition in substrate-controlled continuous stirred tank reactors. Chem Eng Technol 20:403-413

Borowitzka MA (2013) High-value products from microalgae-their development and commercialization. J Appl Phycol 25:743-756

Camacho-Rodríguez J, Cerón-García MC, González-López CV, Fernández-Sevilla JM, Contreras-Gómez A, Molina-Grima E (2013) A low-cost culture medium for the production of Nannochloropsis gaditana biomass optimized for aquaculture. Bioresour Technol 144:57-66

Camacho-Rodríguez J, Cerón-García MC, Fernández-Sevilla JM, Molina-Grima E (2015) Genetic algorithm for the medium optimization of the microalga Nannochloropsis gaditana cultured to aquaculture. Bioresour Technol 177:102-109

Camacho-Rodríguez J, Cerón-García MC, Macías-Sánchez MD, Fernández-Sevilla JM, López-Rosales L, Molina-Grima E (2016) Long-term preservation of concentrated Nannochloropsis gaditana cultures for use in aquaculture. J Appl Phycol 28:299-312

Camacho-Rodríguez J, Cerón-García MC, González-López CV, LópezRosales L, Contreras-Gómez A, Molina-Grima E (2020) Use of continuous culture to develop an economical medium for the mass production of Isochrysis galbana for aquaculture. J Appl Phycol 32:851-863

Cardinaletti G, Messina M, Bruno M, Tulli F, Poli BM, Giorgi G, Chini-Zitelli G, Tredici M, Tibaldi E (2018) Effects of graded levels of a blend of Tisochrysis lutea and Tetraselmis suecica dried biomass on growth and muscle tissue composition of European sea bass (Dicentrarchus labrax) fed diets low in fish meal and oil. Aquaculture 485:173-182

Carvalho AP, Pontes I, Gaspar H, Malcata FX (2006) Metabolic relationships between macro- and micronutrients, and the eicosapentaenoic acid and docosahenaenoic acid contents of Pavlova lutheri. Enzym Microbiol Tech 38:358-366

Cerón MC, García-Malea MC, Rivas J, Acien FG, Fernandez JM, Del Río E, Guerrero MG, Molina E (2007) Antioxidant activity of Haematococcus pluvialis cells grown in continuous culture as a function of their carotenoid and fatty acid content. Appl Microbiol Biotechnol 74:1112-1119

Cerón-García MC, González-López CV, Camacho-Rodríguez J, López-Rosales L, García-Camacho F, Molina-Grima E (2018) Maximizing carotenoid extraction from microalgae used as food additives and determined by liquid chromatography (HPLC). Food Chem 257:316-324

Chen M, Tang H, Ma H, Holland TC, Simon Ng, KY, Salley SO (2011) Effect of nutrients on growth and lipid accumulation in the green algae Dunaliella tertiolecta. Bioresour Technol 102:1649-1656
Chisti Y (2007) Biodiesel from microalgae. Biotechnol Adv 25:294-306

Fábregas J, Otero A, Morales ED, Arredondo-Vega BO, Patino M (1998) Modification of the nutritive value of Phaeodactylum tricornutum for Artemia sp. in semicontinuous cultures. Aquaculture 169:167-176

Gallardo Rodríguez JJ, Sánchez Mirón A, Cerón García MdC, Belarbi EH, García Camacho F, Chisti Y, Molina Grima E (2009) Macronutrients requirements of the dinoflagellate Protoceratium reticulatum. Harmful Algae 8:239-246

García-Camacho F, Gallardo-Rodríguez JJ, Sánchez-Mirón A, Chisti Y, Molina-Grima E (2011) Genetic algorithm-based medium optimization for a toxic dinoflagellate microalga. Harmful Algae 10:697-701

Gong X, Chen F (1997) Optimization of culture medium for growth of Haematococcus pluvialis. J Appl Phycol 9:437-444

Hoffmann M, Marxen K, Schulz R, Vanselow KH (2010) TFA and EPA productivities of Nannochloropsis salina influenced by temperature and nitrate stimuli in turbidostatic controlled experiments. Mar Drugs 8:2526-2545

Huerlimann R, de Nys R, Heimann K (2010) Growth, lipid content, productivity, and fatty acid composition of tropical microalgae for scale-up production. Biotechnol Bioeng 107:245-257

Lin YH, Chang FL, Tsao CY, Leu JY (2007) Influence of growth phase and nutrient source on fatty acid composition of Isochrysis galbana CCMP 1324 in a batch photoreactor. Biochem Eng J 37:166-176

Link H, Weuster-Botz D (2006) Genetic algorithm for multi-objective experimental optimization. Bioprocess Biosyst Eng 29:385-390

López-Rosales L, García-Camacho F, Sánchez-Mirón A, Chisti Y (2015) An optimal culture medium for growing Karlodinium veneficum: progress towards a microalgal dinoflagellate-based bioprocess. Algal Res 10:177-182

Lubián LM, Montero O, Moreno-Garrido I, Huertas IE, Sobrino C, González-del Valle M, Parés G (2000) Nannochloropsis (Eustigmatophyceae) as source of commercially valuable pigments. J Appl Phycol 12:249-255

Marteijn RC, Jurrius O, Dhont J, de Gooijer CD, Tramper J, Martens DE (2003) Optimization of a feed medium for fed-batch culture of insect cells using a genetic algorithm. Biotechnol Bioeng 81:269-278

Muffler K, Retzlaff M, van Pée KH, Ulber R (2007) Optimisation of halogenase enzyme activity by application of a genetic algorithm. J Biotechnol 127:425-433

Muller-Feuga A (2000) The role of microalgae in aquaculture: situation and trends. J Appl Ichthyol 12:527-534

Naumann T, Çebi Z, Podola B, Melkonian M (2013) Growing microalgae as aquaculture feeds on twin-layers: a novel solid-state photobioreactor. J Appl Phycol 25:1413-1420

Norsker N-H, Barbosa MJ, Vermuë MH, Wijffels RH (2011) Microalgal production - a close look at the economics. Biotechnol Adv 29:24-27

Patil V, Källqvist T, Olsen E, Vogt G, Gislerød HR (2007) Fatty acid composition of 12 microalgae for possible use in aquaculture feed. Aquacult Int 15:1-9

Pereira da Costa D, Campos Miranda-Filho K (2020) The use of carotenoid pigments as food additives for aquatic organisms and their functional roles. Rev Aquac 12:1567-1578

Perez-Velazquez M, Gatlin DM III, González-Félix ML, García-Ortega A (2018) Partial replacement of fishmeal and fish oil by algal meals in diets of red drum Sciaenops ocellatus. Aquaculture 487:41-50

Pham MA, Byun H-G, Kim K-D, Lee S-M (2014) Effects of dietary carotenoid source and level on growth, skin pigmentation, 
antioxidant activity and chemical composition of juvenile olive flounder Paralichthys olivaceus. Aquaculture 431:65-72

Procházková G, Brányiková I, Zachleder V, Brányik T (2014) Effect of nutrient supply status on biomass composition of eukaryotic green microalgae. J Appl Phycol 26:1359-1377

Rodríguez-Ruiz J, Belarbi E, García Sánchez JL, Alonso DL (1998) Rapid simultaneous lipid extraction and transesterification for fatty acid analyses. Biotechnol Tech 12:689-691

Rohani-Ghadikolaei K, Wing-Keong N, Abdulalian E, Naser A, Yusuf A (2012) The effect of seaweed extracts, as a supplement of alternative culture medium, on the growth rate and biochemical composition of the microalga, Isochrysis galbana (Park 1949). Aquac Res 43:1487-1498

Rubio FC, Fernández FGA, Pérez JAS, Camacho FG, Grima EM (1999) Prediction of dissolved oxygen and carbon dioxide concentration profiles in tubular photobioreactors for microalgal culture. Biotechnol Bioeng 62:71-86

Sales R, del Carmen C-G, Navarro-López E, González-López CV, Tsuzuki MY, Acién-Fernández FG, Alarcón-López FJ, MolinaGrima E (2020) Processing Nannochloropsis gaditana biomass for the extraction of high-value biocompounds. J Appl Phycol 32:3113-3122

Sirakov I, Velichkova K, Stoyanova S, Staykov Y (2015) The importance of microalgae for aquaculture industry. Int J Fish Aquat Stud 2:81-84

Stefels J, van Leewe MA (1998) Effects of iron and light stress on the biochemical composition of Antarctic Phaeocystis sp. (Prymnesiophyceae): I. Intracellular DSMP concentrations. J Phycol 34:486-495
Sukenik A, Wahnon R (1991) Biochemical quality of marine unicellular algae with special emphasis on lipid composition. I. Isochrysis galbana. Aquaculture 97:61-72

Sun Z, Wang X, Liu J (2019) Screening of Isochrysis strains for simultaneous production of docosahexaenoic acid and fucoxanthin. Algal Res 41:101545

Taelman SE, De Meester S, Roef L, Michiels M, Dewulf J (2013) The environmental sustainability of microalgae as feed for aquaculture. A Life Cycle perspective. Bioresour Technol 150:513-522

Tzovenis I, De Pauw N, Sorgeloos P (1997) Effect of different light regimes on the docosahexaenoic acid (DHA) content of Isochrysis aff. galbana (clone T-ISO). Aquac Int 5:489-507

Veljkovic VB, Nikolic S, Lazic ML, Engler CR (1995) Oxygen transfer in flasks shaken on orbital shakers. Hem Ind 49:265-272

Vizcaíno AJ, López G, Sáez MI, Jiménez JA, Barros A, Hidalgo L, Camacho-Rodríguez J, Martínez TF, Cerón-García MC, Alarcón FJ (2014) Effects of the microalga Scenedesmus almeriensis as fishmeal alternative in diets for gilthead sea bream, Sparus aurata, juveniles. Aquaculture 431:34-43

Vizcaíno AJ, Saéz MI, López G, Arizcun M, Abellán E, Martínez TF, Cerón-García MC, Alarcón FJ (2016) Tetraselmis suecia and Tisochrysis lutea meal as dietary ingredients for gilthead sea bream (Sparus aurata L.) fry. J Appl Phycol 28:2843-2855

Zhu CJ, Lee YK (1997) Determination of biomass dry weight of marine microalgae. J Appl Phycol 9:189-194

Publisher's note Springer Nature remains neutral with regard to jurisdictional claims in published maps and institutional affiliations. 